\title{
Reconceptualising academic development as community development: lessons from working with Syrian academics in exile
}

\author{
Tom Parkinson $^{1} \cdot$ Kevin McDonald ${ }^{2} \cdot$ Kathleen M. Quinlan ${ }^{1}$
}

Published online: 5 July 2019

(C) The Author(s) 2019

\begin{abstract}
This paper focuses on academic development for Syrian academics in exile. Academic development first emerged in resource-rich, global North environments including the UK, the USA, Australia, and Scandinavia nearly 50 years ago as reported by Gosling (International Journal for Academic Development, 14(1):5-18, 2009), and the majority of research studies in this field focus on activities in global North, resource-rich, institutional settings. Yet academics in resource-poor, [post-] conflict and post-colonial contexts face different challenges and circumstances, and have different academic development needs. This paper extends the conceptual and contextual scope of this field by investigating the experiences and academic development needs of Syrian academics in exile, and interrogating the concept of academic development within that context. It establishes the background context of Syrian academia in exile, before summarising the nature and aims of the Council for At Risk Academics (Cara) Syria Programme. It then outlines the study's methodology, before presenting the findings of a thematic analysis of a multi-level data set. It then interrogates the concept and normative terrain of academic development in light of these findings, and proposes a model for academic community development to support academic communities in exile, and marginalised academic communities more widely.
\end{abstract}

Keywords Academic development $\cdot$ Crisis $\cdot$ Syria $\cdot$ Higher education $\cdot$ Exile $\cdot$ Community development

Tom Parkinson

t.parkinson@kent.ac.uk

Kevin McDonald

K.mcdonald@mdx.ac.uk

Kathleen M. Quinlan

K.m.quinlan@kent.ac.uk

1 Centre for the Study of Higher Education (CSHE), University of Kent, Canterbury, Kent CT2 7NZ, England

2 Middlesex University, London, England 


\section{Introduction}

Academic development, variously termed faculty development, instructional development, and educational development, first emerged in resource-rich, global North environments including the UK, the USA, Australia, and Scandinavia nearly 50 years ago (Gosling 2009). Although it has since gained traction around the globe and associations of professional academic developers now exist in some twenty-four countries including developing countries such as Ethiopia and Sri Lanka (International Consortium for Educational Developers (ICED) 2017), the majority of research studies in this field concern academic development activities within resource-rich institutional settings. Practical models and guidelines for academic development also emanate from global North countries; the UK's Higher Education Academy is cultivating international partnerships with a range of countries that do not have established educational development programmes of their own, while a recent European Science Foundation report on the professionalisation of teachers in higher education (Pleschová et al. 2013) offered Western European models of academic development for application in Eastern European contexts.

Yet resource-poor, [post-] conflict and post-colonial contexts present different challenges and circumstances from those in the origins of the field of academic development. This paper extends the conceptual and contextual scope of this field by interrogating the concept of academic development within the context of the Council for At Risk Academics' Syria Programme (hereafter Cara SP), an initiative that supports academic development for Syrian academics in exile in neighbouring countries. Through an analysis of the academic development needs of Syrian academics on the Cara SP, we address the following research questions:

1. What barriers to engagement in academic practice are experienced by Syrian academics in exile in Turkey?

2. What are the academic development needs of Syrian academics in exile in Turkey?

3. What are the implications of the barriers and needs of Syrian academics in exile for the conceptualisation of academic development?

We begin by accounting for the background contexts of Syrian higher education before and since 2011, the current refugee crisis, and Syrian academics in exile, before summarising the nature and aims of the Council for At Risk Academics (hereafter Cara) and the Syria Programme (hereafter SP). We then outline the study's methods, based on a large group process design (Martin 2005) implemented through a residential event held in Istanbul. We then answer the first and second research questions through a thematic analysis of a multi-level data set comprising topical summaries and outputs from the event and the individual professional development plans (PDPs) of twenty-five ${ }^{1}$ Syrian academics exiled in Turkey. We then turn our attention to the third research question, interrogating the concept and normative terrain of academic development. We call for a reappraisal of the boundaries of academic development in order to encompass work undertaken outside of institutional settings, and propose a model for academic community development to support academic communities in exile and marginalised academic communities more generally.

\footnotetext{
${ }^{1}$ Twenty-nine academics participated in the event in total-four were unable to stay for the full duration of the event and were thus unable to complete a PDP.
} 


\section{Syrian higher education before and after 2011}

Syria's education sector was relatively well developed prior to the outset of the current crisis (King 2016). Around 25\% of young people benefitted from post-secondary education in 2010/ 2011 (King 2016), reflecting the wider trend of massification of higher education across the Middle East that began in the 1990s. Significant reforms in Syria from 2000 saw large increases both in the number of students and institutions accommodating them (Bakarat and Milton 2015). The quality of provision has been called into question, however, with some noting 'a number of deficits pre-conflict in educational capacity' (Avery and Said 2017, p. 107), and 'regress[ion] [...] both in terms of [universities'] overall contribution to knowledge creation and to nation-building (Bakarat and Milton 2015, p. 2).

Since 2011, Syria has suffered from the world's worst conflict-derived humanitarian crisis since the Cold War (Avery and Said 2017), and its higher education sector has been decimated in physical, human, institutional, and social terms (Bakarat and Milton 2015). Academic communities have been disproportionately affected by the crisis (Anonymous 2016; Bakarat and Milton 2015; Bariscil 2017; Watenpaugh et al. 2014), as evidenced by targeted attacks such as the bombings of Aleppo and Damascus universities in 2013 which killed almost a hundred students, and the widespread persecution of academic staff (Barascil 2017; Watenpaugh et al. 2014). In 2012/2013, almost all of the country's registered students had their studies interrupted or ended (Vollman 2016). Between 1500 and 2000 academics have fled Syria to neighbouring countries or Europe (King 2016), where they are often unable to continue their academic work due to legal status, language barriers, psychological trauma, unrecognised qualifications, and other factors.

Turkey has taken the largest proportion of refugees fleeing the current crisis, with 2.7 million Syrians officially domiciled in the country (İçduygu and Millet 2016). Their status is subject to the vagaries of national and supranational policy, however, resulting in a precarious experience for many. The 'temporary protection' status of most Syrian refugees in Turkey implies impermanence, despite the Turkish authorities 'circuitously accept[ing] the likelihood of a process whereby the protracted displacement of Syrians turns into their long-term, and even permanent, settlement' (İçduygu and Millet 2016, p. 2). The conditions of status can impose restrictions on many aspects of refugees' lives, such as the ability to work in certain sectors, or to travel beyond and even within Turkey. These restrictions can curtail Syrian academics' prospects, particularly those without official documentation; the Union of Free Syrian Academics (UFSA) estimates that $70 \%$ of Syrian academics in Turkey lack passports, and many lack proof of their academic qualifications (Ammar 2016).

As noted above, Syria had a developed higher education system prior to the conflict, and the refugee population's mean education level is comparatively high. King (2016) suggests these features have led to a heightened awareness of higher education's potential role in contributing meaningfully to humanitarian and development efforts. Furthermore, higher education was declared a strategic priority for the first time in the United Nations High Commission for Refugees' Education Strategy 2012-2016 (UNHCR 2012), and there is a growing sense that higher education can act 'as a bridge between emergency response and sustainable development' (Sherab and Kirk 2016, p. 13). Bakarat and Milton (2015) argue that higher education's potential lies not only in supplying skills needed to rebuild physical and economic infrastructure, but also in supporting social cohesion and sustaining intellectual heritage. In particular, they highlight the importance of links between international academic communities and those in crisis contexts 'to help maintain a minimum level of intellectual 
vibrancy' (p. 4), warning that in Iraq 'over a decade of war and economic blockades cut academia off from international exchanges of knowledge and resources' (p. 4).

Despite this increase in awareness of higher education's importance to crisis recovery, Syrian scholars are frustrated by the lack of support they are receiving from the international community (e.g. Abdo 2015; Watenpaugh et al. 2014). Organisations supporting Syrian academics, such as the Institute of International Education's Scholar Rescue Fund (IIE-SRF) and Cara, are already working beyond capacity (Abdo 2015; King 2016). Historically, many such organisations have focused on securing placements and fellowships for individual academics in international universities. While transformational for individuals, this approach is resource-heavy and limited to academics who are able to travel. Furthermore, it has been argued that focusing on foreign solutions risks de-centring higher education from affected regions, leading to brain-drain, structural dependency, and, ultimately, hindering sustainability (Avery and Said 2017).

In response to these challenges, a number of initiatives have sought instead to support academic communities in situ, in exile or in Syria. ${ }^{2}$ The Cara $\mathrm{SP}^{3}$ has focused on supporting academics exiled in Jordan, Lebanon, and Turkey through capacity-building activities. Given the complexities of the Syrian crisis, there is no blueprint to follow, but the project is undergirded by the principle that 'agenda-setting [should be] determined by the people concerned' (Avery and Said 2017, p. 106). Accordingly, the programme began in 2016 with a series of consultation activities (Cara 2016) involving members of the Syrian academic community in exile in Turkey who were registered with Cara $(n=50)$. These consultations informed the strategic objectives of a pilot phase, divided across three strands of activity: English for Academic Purposes; Research Incubation (identifying opportunities for participants to collaborate in international research projects); and Academic Skills Development. This third strand supports participants in developing and sustaining their academic practice through training, resources, and networking opportunities and is the focus of this paper. We examine the academic development needs of Syrian academics in exile, in order to develop new conceptions of and orientations to academic development that respond to the complexities of crisis and post-conflict contexts.

\section{Method}

To be responsive to participants' unfolding needs, academic development on the Cara SP is guided and structured according to an action research framework. This paper is based on the opening, reconnaissance stage; an in-depth, theoretical discussion of the wider action research design is provided in a separate methodological paper (Parkinson 2018). In this section, we describe the participants and summarise our approach to data collection and analysis.

Participants The twenty-nine participants in the study were Cara-registered Syrian academics domiciled in Turkey, who had all met Cara's eligibility criteria for support - namely that they had been employed as academics or registered as doctoral researchers prior to the crisis. All but three participants held doctoral degrees, and two of those without had had their doctoral

\footnotetext{
${ }^{2}$ Examples include the UNHCR's DAFI programme, and the Jamiya project, launched in 2016 in conjunction with the University of Gothenburg. The focus of both projects is students rather than academics.

${ }^{3}$ Cara continues to seek international placements for Syrian academics via its Fellowship Scheme.
} 
studies interrupted. Nine participants had undertaken their doctoral studies abroad (Russia, Egypt, and Germany). Disciplinary fields included agriculture, chemistry, engineering, mathematics, computing, economics, history, and theology (Fig. 1). A range of pre-crisis seniority levels was represented (Fig. 2), and ages ranged from thirty to sixty. All but one of the participants were male. Over one-third of the group were unemployed at the time of data collection. Of the remainder, a minority were employed full-time and the rest undertook varying degrees of part-time work, including unpaid volunteer work (Fig. 3).

Large group process A two-day residential large-group process (hereafter LGP) event was held in Istanbul in April 2017. LGPs originate from the domains of social psychology and organisational management (see Parkinson 2018), and are defined by Martin (2005) as events aimed at engaging communities in thinking through and planning change (p. 200). An LGP approach was chosen because it offered a means of collecting rich group- and individual-level data from participants within a time-limited context, as well as simultaneously offering a meaningful learning and planning opportunity for participants. LGP design is flexible (Bryson and Anderson, 2000; Martin 2005), but should comprise activities that stimulate dialogue. Our design was informed by a number of models (e.g. FHWA 2015; Gross and Jacobs 2013; Owen, 2008). As Martin (2005) notes, large-group intervention 'is [not] a matter of following a recipe [as] each setting presents its own challenges' (p. 208).

As the participants' level of English varied, the LGP was conducted in Arabic. Two interpreters were present throughout the two days, translating communications between the participants and facilitators, participants' discussions with each other (for the benefit of the facilitators), and written outputs. The workshop was facilitated by three UK-based academics, including the first and second authors of this paper. The participatory activities spanned one full day. Participants wrote a personal development plan (PDP) as an individual writing task the following day.

First, participants were asked to write or draw on post-it notes anything that the phrase 'being an academic' made them think of, and to stick their responses onto a banner fixed to the wall. They were encouraged not to self-edit. When the banner was full, the participants read and discussed the responses, and took photos for the following activity.

Second, participants collaboratively organised the responses into broad categories, working in groups of five or six. Similar to coding within qualitative analysis, this process led to the emergence of a thematic framework, and provoked participants to

- Pure sciences $\quad$ Applied sciences $\quad$ Social sciences Humanities

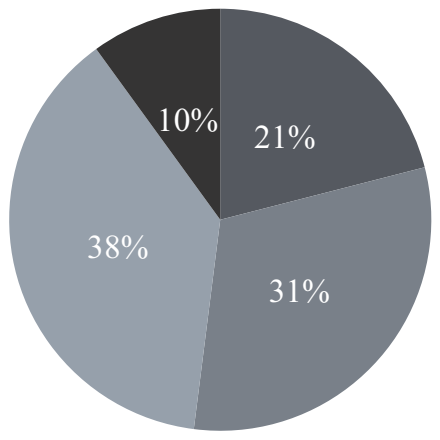

Fig. 1 Participants' disciplinary field 


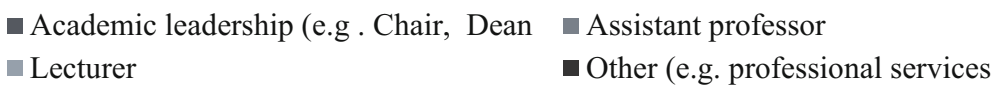

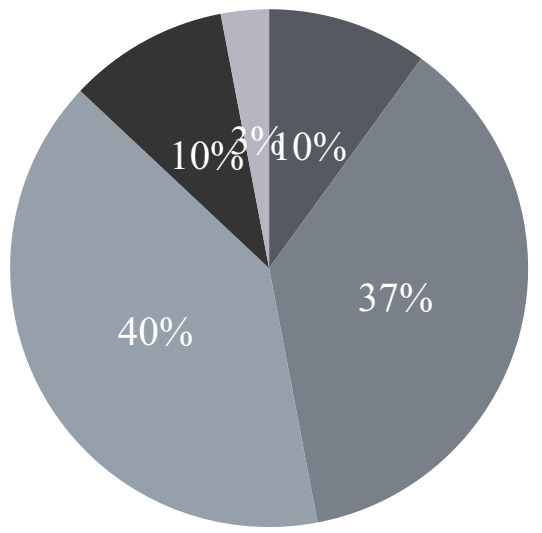

Fig. 2 Participants' professional status in Syria prior to 2011

verbalise their ideas, synthesise different strands of thought, and gain insight into each other's understandings. Group work was an important feature of the event design, because working collaboratively towards consensus can also bolster morale and rapport and build collective ownership of emergent themes.

The category names were gathered from the groups and written onto a whiteboard. The facilitator of this exercise worked with the whole group to explore the categories conceptually, identify duplication across the categories, or create new categories that might house two or more of those previously identified. Through this process, a list of twenty-seven thematic categories was reduced to a list of five: responsibility, disciplinarity, teaching, research, and collaboration.

Participants chose the theme that most interested them, resulting in five working groups. Groups then explored their theme discursively, reflecting on their experiences and identifying challenges and opportunities. Groups were encouraged to keep their discussion general at this stage rather than focus on the specificities of their own individual circumstances. Each group

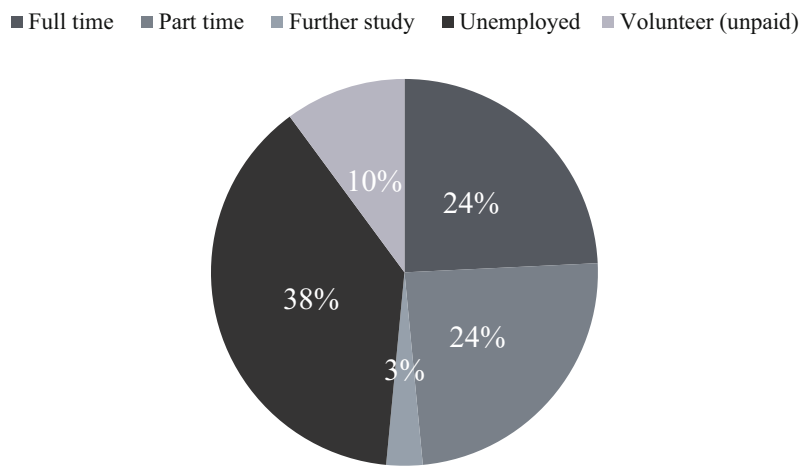

Fig. 3 Participants' current employment status 
recorded their insights on posters which they presented to the whole cohort for discussion, allowing members of other groups to contribute. All participants were invited to record additional thoughts or insights on post-it notes and add them to the relevant poster. Members of the facilitation team took notes throughout the day, recording salient insights, themes, and issues as they emerged.

Finally, participants wrote a personal development plan (PDP), using the five emergent categories as subheadings and identifying challenges and opportunities associated with each. ${ }^{4}$ While the group activities had focused on general concerns, participants were encouraged to focus on their personal circumstances in their PDPs. Copies of the PDPs were collected from participants and translated into English for analysis.

\section{Analysis}

As a first phase of analysis, an inductive approach informed by Thomas (2016) was used to code a qualitative data set comprising (a) flipchart posters from the LGP ( $n=10$, including affixed post-it notes, translated into English); (b) facilitators' notes of the LGP discussions (several pages); and (c) individual PDPs ( $n=25$, each one to three pages). These data provided insight into both group-level consensus and individuals' academic development needs.

Given the inductive nature of the LGP activities themselves, and the participatory philosophy underpinning the project, the thematic categories of responsibility, disciplinarity, teaching, research, and collaboration were preserved as an initial framework for this analysis. Subsequently, the authors read and re-read the data to identify dominant themes and issues within each category, and points of overlap across categories, and elaborated the category names accordingly. Initially, the first and second authors undertook the sub-category coding independently before comparing for consistency (which did not result in substantially different analyses). As a second phase, the thematic coding was written up in narrative form, with verbatim quotations.

\section{Results}

In this section, we present the findings according to the categories that emerged from thematic analysis. Verbatim quotations from the individual participants' PDPs have been chosen on the basis of their thematic representativeness, and to ensure that a breadth of voices are represented.

Responsibility: towards Syria, the scientific community, their dependents, and themselves Most participants' primary motivation was a sense of responsibility for rebuilding and leading Syria's future. This sense of purpose superseded concerns for personal reward or advancement. Many were already involved in projects with this focus; some regularly crossed back into Syria to teach former students in ad hoc, temporary settings, while others were exploring possibilities for delivering higher education via web-based systems. As experts familiar with the Syrian context, they felt uniquely placed to lead their country's eventual recovery, which required them to work hard and maintain their expertise as a point of national

\footnotetext{
${ }^{4}$ In practice, not all PDPs followed this suggested structure. Nonetheless, they provided valuable insight into individuals' experiences.
} 
duty. For many, this duty included learning English to enable them to build international academic networks and represent Syria at international conferences. They hoped to serve as examples, both to the population still in Syria and to other Syrian academics in exile. The group tasked with exploring responsibility during the LGP proposed three categories: social responsibility, related to supporting and educating their communities within and outside of Syria and working towards the eventual rebuilding of Syria; human responsibility, related to applying their expertise in humanitarian work; and scientific responsibility, which meant upholding academic integrity and good standing within disciplinary communities. One participant explained their personal sense of responsibility:

My responsibility as a researcher is to repay the country I was educated in; therefore my main responsibility is to work within any zone considered safe in my country. My responsibility towards the world is to employ my research for the good of humanity (SA19)

Many of the PDPs and contributions to the LGP discussions highlighted the important role of academics and universities in the reconstruction of Syria. While much of this discussion focused on addressing the skills deficit, others approached this responsibility in terms of moral and civic values:

It is my moral responsibility to continue learning and teaching new generations $[\ldots]$ to plant the values of patriotism, democracy, freedom and human rights in new generations so that we do not relive the tragedy of war and destruction in our country (SA5)

It is a social, moral and patriotic responsibility towards my people to carry out such research, but current conditions are not encouraging (SA23)

Many highlighted the importance of universities engaging with wider society. Several underlined that Syrian universities lacked a tradition of wider public engagement, so this was a new area for development. Some were seeking opportunities to apply their expertise beyond educational settings. For example:

[I try to] take part in efforts to reach realistic solutions for the Syrian crisis by providing advice to the decision-makers in the establishments and bodies working on the Syrian question (SA13)

Many participants were emphatic that these responsibilities were not theirs alone and should be shared by the international community. For example:

The most complicated problem we face today is education, and [in particular] contributing in the teaching of Syrians who are no longer able to attend schools and universities. This requires a huge international effort (SA15)

[and]

Providing support for [Syrian researchers] is the responsibility of humanitarian organisations [...] Attention must be directed at educating people wherever they are. Huge efforts must be directed to conflict zones, such as inside Syria. Education is the right of every human being (SA19) 
Disciplinarity: working within and contributing to one's discipline Participants reported few or no opportunities to work within their own discipline in Turkey. Most who had found employment in Turkish universities were teaching in areas peripheral to their expertise, and felt isolated from their disciplinary communities as a result. This situation was worse for those who had not secured academic work, and instead had taken up (often unskilled) work in other industries. For this group in particular the lack of access to resources, administrative support, professional or disciplinary bodies, and research facilities such as laboratories had led to a perceived deskilling and erosion of disciplinary expertise. This was demoralising for many, as their discipline was central to their professional identity:

A key to success for any human being, and academics in particular, is to specialise in a particular field because this will increase one's capacity for innovation and development. However, some [Syrian] academics face a number of challenges in that respect, such as a lack of programmes by which they can improve their skills, or the need to work in [a discipline] far removed from what they have studied and specialised in (SA15)

Almost all participants reported difficulty in staying up-to-date with developments within their discipline. Despite profound obstacles, many reported being motivated by a love for their subject. Most were keen to explore opportunities for disciplinary community-building within the cohort of CARA-registered Syrian academics, and within international disciplinary communities. For some, supporting colleagues with interrupted higher degree study to resume their studies was a priority.

Developing teaching skills and approaches relevant to the Syrian context Approximately half of the group were engaged in teaching roles of some kind, either at universities in Turkey (overwhelmingly on an ad hoc basis) or in Syria. In the latter case, participants reported difficulties in connecting theory and practice due to lack of resources (such as laboratory facilities and equipment) and few opportunities to simulate professional, industrial, or other 'real-world' scenarios. High student-staff ratios also presented challenges, and internet connectivity issues within Syria made communicating with students in the periods between faceto-face teaching sessions difficult. Many participants spoke of security and safety concerns impeding teaching in Syria, and others were keen to emphasise the uniqueness of the Syrian context and the need to develop and share context-specific strategies for educating in times of crisis and war and reaching learners whose formal education had ended:

The most complicated problem we face today is contributing to the teaching of Syrians who are no longer attending schools and universities (SA15)

Many participants had found YouTube to be a valuable resource for teaching materials and teacher development activities, and some were delivering teaching to, or supervising, former students online:

I help Syrian students in Syria - as much as I can — by contributing to remote teaching via the internet (SA13)

Participants were unanimous in calling for training opportunities related to teaching, particularly in the areas of technology, pedagogy, and international norms:

University teaching is our main objective [...] and for that I seek to learn methods to assist [me] in the process [of teaching] and also learn [about] the Turkish and international university systems (SA20) 
I'm working on developing my computer skills [...] particularly in programmes relating to teaching, but my problem is the high cost of courses (SA22)

[I want] to develop my teaching methods and skills [and] to become familiar with the teaching experiences of international establishments (SA13)

[Cara should] hold workshops on modern teaching methods for academics (SA10)

[We need] to learn modern teaching methods and strategies, from the internet at least (SA21)

Among those who were not engaged in teaching, some wrote of their lack of official documentation, or visa restrictions as preventing them from applying for teaching roles, while others hoped to improve their language skills in English and/or Turkish to open up more opportunities in teaching.

Research: skills, resources, and opportunities As most participants had doctorates, they were familiar with research methods within their discipline. However, because Syrian universities had not required academics to remain research active, many had focused on teaching and not developed their research profiles through subsequent projects and publications. This lack of opportunities and impetus to engage in applied research was noted by several participants as a cause of deskilling, particularly in practical scientific research. For example:

Being an academic in Syria for 15 years led to a loss of practical skills, because there is little connection between the practical and theoretical in Syrian universities (SA7)

Participants who had stayed research active had done so in their own time for reasons of personal interest and motivation, rather than contractual expectations. War and displacement had inevitably affected these activities, however, and there was a widespread concern that they had deskilled following years of inactivity. During their time in Turkey, most participants had been disconnected from professional and academic networks, making research activity impossible. There was widespread consensus that they needed to participate actively in research in order to (re)engage with international academic communities. Moreover, many believed that establishing collaborative research groups among Syrian academics in exile in Turkey would help affirm their academic identities, and engender a sense of belonging to a Syrian academic community. As one PDP noted:

[Undertaking research] creates a new space for the Syrian academic and helps [them] transfer from a position of loss to a state of security and social, psychological and financial stability (SA16)

Notwithstanding anxieties surrounding deskilling, there was a palpable confidence in their scholarly expertise, and a belief that through internal collaboration they would be able to leverage this to productive ends and 'learn by doing'. The issue of resourcing recurred in the majority of PDPs, particularly with regard to administrative support for networking activities:

[We must] make use of these academics because they have spent their lives to reach this stage in their specialties [and] develop programmes and hold sessions encouraging team 
work among Syrian academics. [But] this also has its problems, especially in the areas of support and management (SA10)

Many highlighted that safety and security issues in Syria made undertaking research there very difficult. Furthermore, research centres in Syria had closed, cutting off access to data, networks, and resources. Some participants had sought to join academic and professional bodies and societies in Turkey, but reported a shortage, particularly in the domain of engineering. As noted under responsibility, forging links with NGOs, think-tanks, and research institutes beyond the university sector was seen as important to achieving impact and completing projects that would provide material benefit to the people of Syria.

Some participants had tried to initiate or take part in research projects in Turkey, but had struggled due to lack of access to networks, scientific and scholarly resources, and funding. For example:

I have had a lot of experience in scientific cooperation, and have founded groups of academics to promote cooperation, but the absence of external funding and the challenges I faced led to the failure of most of the experiments we tried to spread between [Syrian] academics in Turkey and those still in Syria (SA15)

[and]

I was carrying out a number of research projects related to [specified research areas] but I had to stop because I could not find a sponsor organisation (SA1)

Others reported that gaining access to networks and research communities was difficult in Turkey, due to the word-of-mouth nature of collaboration:

There are few opportunities in Turkey for my specialisation and for my level of experience. In the organisations operating in Turkey people are only accepted through personal relationships (SA24)

Organisations in Turkey only employ people they know (SA2)

There are no organisations, universities or scientific bodies [that will] sponsor Syrian academics (SA16)

Some also reported that a lack of a university affiliation posed a barrier to publication through some channels, such as journals hosted by universities. During the group discussions, the participants expressed concern about positions in some newer universities that offer little in the way of resources, scholarly activity, or access to academic communities.

Collaboration: finding ways to participate in international academia Participants wanted to engage in international and interdisciplinary collaboration, and also to collaborate with other Syrian academics on the Cara SP. Many felt that attendance at international conferences was essential for them to gain access to such opportunities, but visa and other legal issues often prevented participants from travelling overseas, cutting them off from international communities. Some participants wanted to undertake exchanges or placements, and saw post-doctoral appointments in international universities as an opportunity to plug into international research 
communities and participate in large-scale projects. Many felt, though, that their lack of training in new research and teaching methods and poor English language skills were obstacles. Others were concerned that qualifications obtained in Syria were not recognised internationally, with some reporting that they had been refused work in Turkey because their Syrian qualifications were not considered commensurate with Turkish qualifications.

For many, the lack of stability in their personal circumstances often made collaborative projects impossible. Individuals reported psychological trauma, financial constraints, precarious living arrangements, and legal complexities as factors inhibiting their engagement with wider academic communities. As such, their plans for development were contingent upon stability in other aspects of their life.

\section{Discussion}

The findings portray academics who are enduring extremely challenging circumstances, yet are remarkably resilient and committed to sustaining their academic practice as a point of moral duty towards Syria, their disciplinary communities, their families, and themselves. It is also clear that they desire and appreciate support from the international community to address barriers to engagement in academic life.

Our first and second research questions - 'what barriers to engagement in academic practice are experienced by Syrian academics in exile in Turkey?' and 'What are the academic development needs of Syrian academics in exile in Turkey?'-have been addressed through an inductive reading of the data, and the findings inform the strategy and delivery of the Cara SP going forward. Priorities include providing skills development opportunities in teaching and research; identifying, sourcing, and securing access to resources for participants; facilitating research collaborations and networking opportunities both within and outside the Cara SP; identifying ways to integrate delivery across the English for Academic Purposes and Academic Development strands; and exploring solutions to issues of accreditation.

While these seemingly straightforward priorities are the focus of ongoing work, we use this section to reflect on the assumptions we make as outsider academic developers in interpreting these barriers and needs, and address our third research question- 'What are the implications of the barriers and needs of Syrian academics in exile for the conceptualisation of academic development?'. This requires us to first interrogate the concept and normative terrain of academic development itself.

As noted in the introduction, academic development refers to a field of practice that first emerged in resource-rich, global North environments (Gosling 2009). There is a tension over the extent to which the field focuses on teaching or academic practice more broadly. While the dominant emphasis is on enhancing teaching and learning (Gosling 2009), some also include researcher development within the ambit of academic development (Leibowitz 2014). The Cara SP project focuses on academic practice broadly, encompassing teaching and research and associated disciplinary skills and knowledge, as well as collaboration.

A second tension in the field is between professional development for individual academic staff within a single institution, which has dominated UK higher education (Gosling 2009), and organisational development as described, for example, in Sweden (Mårtensson et al. 2011) and Belgium (Quinlan, Clement, Horn 2017). In organisational development, the emphasis is on interventions such as curricular change that focus on departments or programmes, rather 
than individuals. Land (2001) refers to this tension as a dialectic between individual versus institutional foci.

Finally, the field has been criticised for taking a technical, instrumental approach (e.g. Malcolm and Zukas 2001) that merely serves the needs of the employing institution, rather than probing deeper issues such as the ethics of academic practice. While many academic developers act on behalf of managerial mandate, others prefer to distance themselves from managerial agendas, particularly if they are seen as at odds with individual academics' wellbeing and autonomy (Clegg, 2008). Land (2001) described this third key tension as a dialectic between domesticating versus liberating.

In reflecting on these second and third tensions, we see that, unlike the contexts assumed in most academic development literature, and the contexts in which we routinely work, the Cara SP lacks an institutional setting. All of the studies referenced in Sugrue et al.'s (2017) systematic review of academic development literature between 1995 and 2015 take place in college or university contexts. Sugrue et al. (2017) assert that 'dedicat[ion] to helping colleges and universities function effectively as teaching and learning communities' (Felten et al. 2007, 93, cited in Sugrue et al. 2017, p. 1) is a persistent aspect of academic developers' professional responsibility, and identify a preoccupation in the literature with academic developers' influence on institutional practice and strategic leadership.

Insofar as the field of academic development is tacitly, if not explicitly, institutionally bounded, we need to rethink this normative boundary to encompass work such as the Cara SP project. For example, theoretical frameworks and conceptual models arising from empirical work, such as Land's (2001) oft-cited and enduring (e.g. Hall, 2018) taxonomy of orientations to academic development, are institutional in scope and focus, limiting their applicability in non-institutional contexts such as the Cara SP.

The assumption of an institutional frame of reference is so entrenched in the scholarship of academic development that even recent calls to broaden the field's purview (e.g. Sutherland 2018; Stensaker, 2018) do not identify or interrogate it. For example, in a recent special issue of the International Journal of Academic Development, editor Sutherland (2018) suggests that academic developers 'constrain [them] selves - and ultimately the potential of the academic development project - by cleaving to too narrow a conception', and argues that they should be 'more capacious, and more critical, in [their] view of the support [they] provide' (p. 261). Although Sutherland's proposed framework of whole of the academic role/whole institution/ whole person does expand the field, it ultimately reproduces Land's (2001) individual versus institutional dialectic (discussed further below).

As an instance of academic development occurring outside an institutional context, the Cara SP disrupts the normative boundaries of academic development, offering the potential to advance the field contextually and conceptually. It prompts us to reconsider what does or should bind and define academic development. By definition, the Cara SP population comprises individuals with common experiences of Syrian academia, displacement, and exile who have come together on the basis of a common expectation that the programme will address their needs, and support them in sustaining their academic practice. Thus, academic development on the Cara SP is bounded not by an employing institution's teaching and learning strategy, but by its participants' common experiences, needs, expectations, and access to opportunity. These features, which we refer to as common interests, are the binding features of a community (Kenny 2016), moving us towards a conception of academic development as community development, rather than as organisational or institutional development. 
Green and Haines (2017) describe community as 'a contingent phenomenon dependent on a number of conditions to achieve social interactions in pursuit of mutual interest' (p. 2). Green and Haines argue that social interaction and mutual interest are the features that distinguish community from purely geographical concepts such as neighbourhood. We suggest that communities of interest, such as the Cara SP community, possess these same features, and their sustainability depends upon supporting these features. Academic development on the Cara SP should therefore facilitate the development of community as well as development for the community (Green and Haines 2017), for participants' common interests to be effectively pursued.

Furthermore, our findings demonstrate the importance of involving exiled Syrian academics in agenda-setting and strategic planning for their own academic development, as they have a wealth of experience and expertise in relation both to the situation in Syria and the needs of the community in exile. As academic developers from global North, resource-rich contexts, our lack of experience and understanding of the realities of academic life in exile denies us the authority to set an academic development agenda along normative lines. Our findings thus lend weight to calls for international responses that are rooted in sustainable, collaborative models (Avery and Said 2017). What, then, is the role of the outsider academic developer (hereafter OAD) in academic community development? Academic developers working with marginalised communities of interest are in a position to provide indispensable support by being attentive and responsive to their felt needs and chosen priorities and, drawing on their privileged positions, facilitating access to resources and networks.

However, this role formulation highlights some political implications of academic community development. Kenny (2016) describes a tension in community development between ameliorative and transformative approaches. Ameliorative approaches focus on improving the experiences of communities under existing conditions while transformative approaches address the structures that disadvantage those communities. These models map onto epistemologies of social cooperation and social conflict, respectively, and also onto the distinction between capacity building and community organising models, as described by Kenny (2016) and Stoecker (2014). Stoecker (2014) describes capacity building as a de-politicised approach that emphasises selfmanagement capacities but does not challenge political-economic structures. In contrast, community organising seeks to muster power though directly confronting structural inequality. Stoecker (2014) argues that the incompatibility of these models can undermine community development projects that incorporate both community organising and capacity building.

These observations are pertinent to academic development on the Cara SP. On the one hand, the Syrian academics on the Cara SP sit at the periphery of international academia and, as shown in the findings presented above, seek opportunities to gain a foothold at its centre. The OADs' position at the centre affords access to social, cultural, and material capital, which they can distribute outwards by providing access to resources and supporting participants through ameliorative capacity building in relation to the normative practice of the academic centre. Yet this approach arguably capitulates to structural inequalities inherent to international academia, reinforces the centre's authority over the periphery, and effects structural dependency. On the other hand, challenging the norms of the academic centre might ward against dependency, but would likely inhibit participants' access to power. This dilemma is exemplified in academic publishing norms, where Anglophone dominance in academic publishing both derives from and 
reinforces an Anglophone academic centre (Lillis, Magyar and Robinson-Plant, 2010). NonAnglophone, peripheral academics stand greater chances of achieving purchase at the centre by developing their English and normative academic literacies, but this does little to redress the balance of power at a structural level.

Ultimately it is not for outsiders to decide what is good for a community, and in the context of the Cara SP, adopting a participant-driven approach will engender an academic development agenda that corresponds directly to the choices of participants. Yet OADs on the Cara SP, and OADs working with other marginalised academic communities, must be prepared for these complexities to arise. In the final section of this paper, we propose a conceptual framework for academic community development, and suggest some implications for academic community development beyond this particular case study.

\section{A model for academic community development}

Although academic development on the Cara SP is not bound by an institution, a distinction between group-level and individual-level concerns is still pertinent. The findings presented above demonstrated common themes across the group- and individual-level data, even as the individual PDPs also detailed different and more specific needs of individual participants. As Kenny (2016) noted, 'communities are not uncomplicated homogeneous entities [but rather] are multidimensional and fragmented by different inequalities' (p. 24). A model for academic community development must therefore accommodate heterogeneity within the community and attend to individuals' development needs. We propose therefore a first dimension of community-focused in dialectic with individual-focused. This shift is more than a minor semantic modification of the entrenched institutional-individual dialectic (Land 2001). A focus on the 'common interests' of a community forces us to listen to the voices of that community and characterise its unique position. In a context of conflict and exile, this helps us in realising the potential of higher education as part of the United Nations High Commission for Refugees' Education Strategy 2012-2016 (UNHCR 2012), and fulfilling its role 'as a bridge between emergency response and sustainable development' (Sherab and Kirk 2016, p. 13). More generally, focusing on communities moves us towards an academic development agenda focused on responsive support and sustainability.

Drawing on Kenny (2016), we propose an alleviating-transformative dimension. This dimension highlights the difference between a liberal and a more radical orientation and focuses attention on structural and cultural elements, rather than institutional elements. In combination with a community focus, the transformative end of this dialectic gives space for the moral discourse that so strongly characterised the motives of our participants. Transforming post-conflict contexts requires attention to and development of curricular approaches rooted in social reconstruction and pedagogical approaches that have healing potential for a society (e.g. Britzman 2000; Zembylas 2013). Such approaches may be outside the standard repertoire of academic development in the Global North.

Finally, we propose a third dimension, needs-based-asset-based. Needs-based approaches to community development assume a resource deficit, and seek to identify and subsequently meet a community's needs by accumulating resources. Asset-based approaches identify and leverage the tangible and intangible resources (assets) the community already possesses (see e.g. Green and Haines 2017; Kretzmann and McKnight, 1993; Russell and Hutzel, 2015). Again, the moral commitment and first-hand experience of the Syrian academics-in-exile can be harnessed for future nation-rebuilding. 
These dimensions can be set against each other to form a three dimensional model (Fig. 4). Each of the octants of the model represents a possible orientation to academic community development.

OADs may move between or across these orientations in line with the choices of the community and the changing contingencies of a particular context. At this early stage, for example, academic development on the Cara SP mostly aligns with a needs-based, alleviating, community orientation; it is proceeding from needs analysis, and the findings presented in this paper reveal a desire among participants to build their capacity in relation to international academic norms. However, collectively, the Cara SP participants also possess significant intangible assets such as their moral commitment, their resilience, their interconnectedness, and their academic expertise, all of which can be leveraged in pursuit of common interest. As such, a shift towards an asset-based orientation is likely.

Kenny (2016) and Stoecker (2014) identify a tendency among international agencies to approach community development in the global South in a top-down manner, particularly in the case of refugees. Adhering to the principle of community choiceled agenda-setting wards against this tendency, but avoiding outsider control when working with disempowered communities requires further attention. We briefly consider the skills and attributes OADs engaged in academic community development need.

A thorough knowledge of the normative terrain of international academia is essential, both for alleviating and transformative approaches. More generally, OADs engaged in academic

\section{Community-focused}

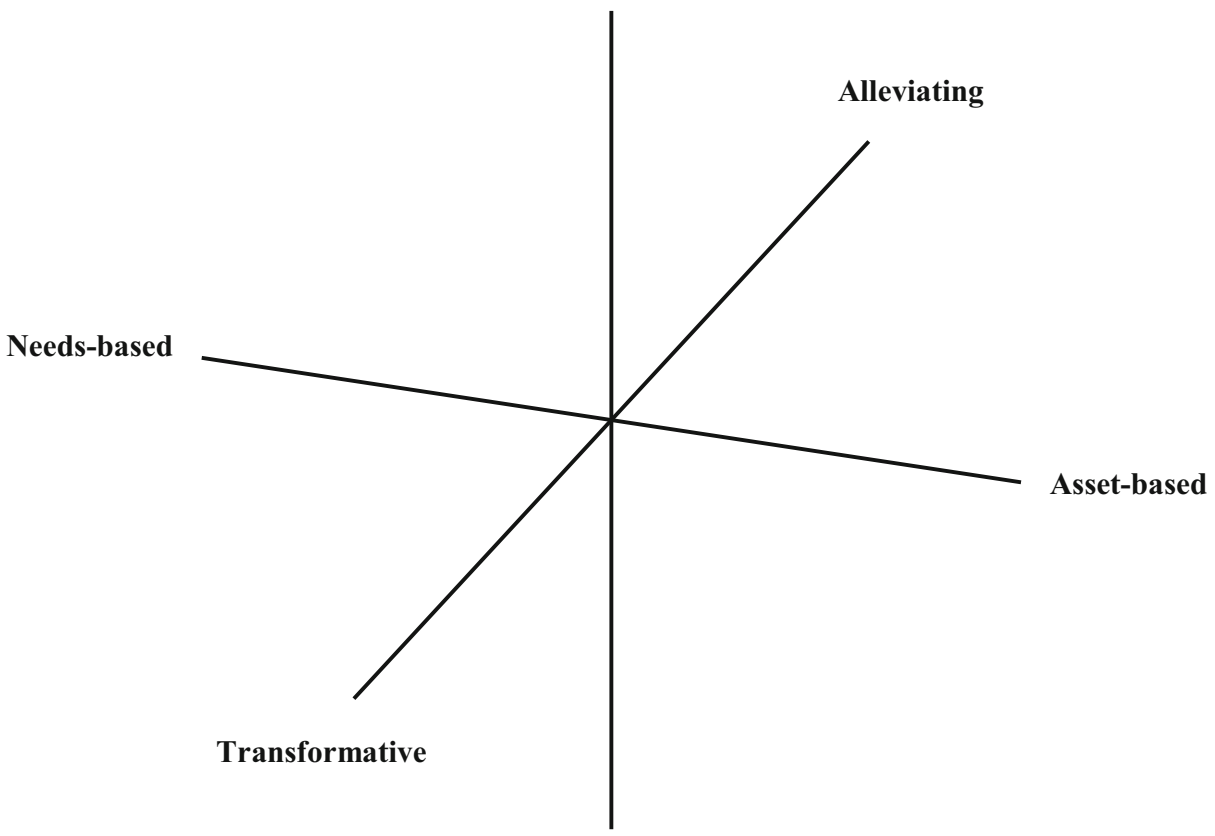

Individual-focused

Fig. 4 Dimensions of academic community development 
community development should be committed to understanding and respecting the experiences and viewpoints of the communities with which they work, and to interrogating their own assumptions. In contexts such as the Cara SP, OADs need to be adept at working in transcultural, disciplinary, and professional boundary spaces (Edwards, 2011; Kenny 2016; Parkinson et al. 2018). Finally, we suggest that skills in facilitating LGPs, a mainstay of community development and action research, are invaluable in supporting bottom-up development work (Parkinson 2018; Parkinson et al. 2018).

The analysis and model presented in this paper provide a basis for formulating approaches to academic community development. The Cara SP is an extremis context (Kenny 2016), but the academic community development construct may also be applied to marginalised groups of academics across a range of contexts. Unbinding academic development from institutional settings opens up the possibility of fostering developmental communities of interest comprised of otherwise isolated individuals and providing tailored support that responds directly to their experiences, interests, and choices.

Acknowledgements We are grateful to the 29 Syrian Academics who participated in the event documented in this paper, and to Professor Mike Barer (University of Leicester) for co-facilitating the event.

\section{Compliance with ethical standards}

Conflict of interest The authors declare that they have no conflict of interest.

Research involving human participants and/or animals Yes (human participants)

Informed consent The project was approved by the corresponding author's institution's Research Ethics and Governance Committee, and informed consent was sought from and granted by all participants.

Open Access This article is distributed under the terms of the Creative Commons Attribution 4.0 International License (http://creativecommons.org/licenses/by/4.0/), which permits unrestricted use, distribution, and reproduction in any medium, provided you give appropriate credit to the original author(s) and the source, provide a link to the Creative Commons license, and indicate if changes were made.

\section{References}

Abdo, W. (2015). To be a Syrian professor: recipe for tragedy. Al-Fanah News and Opinion About Higher Education, February 6. Retrieved 25/10/17 at: https:/www.al-fanarmedia.org/2015/02/syrian-professor-recipe-tragedy/

Ammar, J. (2016). Interview with Jamil Ammar. International Journal of Research from the Front-line, 1(2), $156-162$.

Anonymous. (2016). Syrian academics between reality and ambition: the perspective of a Syrian academic in exile. International Journal of Research from the Front-line, 1(2), 17-22.

Avery, H., \& Said, S. (2017). Higher education for refugees: the case of Syria. Policy and Practice: A Developmental Education Review., 24, 104-125.

Bakarat, S., \& Milton, S. (2015). Houses of wisdom matter: the responsibility to protect and rebuild higher education in the Arab world. Washington, D.C: Brookings Institution.

Bariscil, A. (2017). An emergency academic support - Syrian refugee students in the Turkish higher education. Revista Romaneasca pentru Educatie Multidimensionala, 9(1), 39-49.

Bryson, J., \& Anderson, S. (2000). Applying large-group interaction methods in the planning and implementation of major change efforts. Public Administration Review., 60, 143-162. https://doi.org/10.1111 /puar.2000.60.issue-2. 
Britzman, D. P. (2000). If the story cannot end: deferred action, ambivalence, and difficult knowledge. In R. I. Simon, S. Rosenberg, \& C. Eppert (Eds.), Between hope and despair: the pedagogical encounter of historical remembrance (pp. 27-57). Lanham: Rowman \& Littlefield Publishers.

Council for At Risk Academics (CARA). 2016. Sustaining Syria's Intellectual Capital: Academics as Agents for Change. Programme for Round Table 9th and 10th June 2016. Retrieved 25/10/17 at: http://www.cara. ngo/wp-content/uploads/2016/06/Round-Table-Final-Programme.pdf

Clegg, S. (2008). Academic identities under threat? British Educational Research Journal, 34(3), 329-345.

Edwards, A. (2011). Building common knowledge at the boundaries between professional practices: Relational agency and relational expertise in systems of distributed expertise. International Journal of Educational Research, 50(1), 33-39.

Federal Highway Administration (FHWA) (2015). Public involvement techniques for transportation decisionmaking. US Department of Transportation Federal Highway Administration.

Felten, P., Kalish, A., Pingree, A., \& Plank, A. (2007). To improve the academy: Resources for faculty, instructional and organisational development. In D. Robertson \& D. L. Nilson (Eds.), Towards a Scholarship of Teaching and Learning in Educational Development (pp. 93-108). San Francisco: Jossey-Bass.

Gosling, D. (2009). Educational development in the UK: a complex and contradictory reality. International Journal for Academic Development, 14(1), 5-18.

Green, G. P., \& Haines, A. L. (2017). Asset building and community development. (4th Ed.). Thousand Oaks: Sage.

Gross, C., \& Jacobs, A. (2013). From Tahrir Square to open space: Practical experiences with open space Technology in Egypt. Journal of Social Science Education., 12(1), 50-58.

Hall, J. (2018). Developers in a time of uncertainty and challenge. Keynote address at staff and educational development association (SEDA) conference, Birmingham, England, UK. November 15, 2018. Abstract retrieved 09/06/19 at: https://www.seda.ac.uk/resources/files/Julie\%20Hall\%20Keynote\%20Address.pdf

İçduygu, A., \& Millet, E. (2016). Syrian refugees in Turkey: insecure lives in an environment of pseudointegration. Istanbul: Koç University Press.

International Consortium of Educational Developers (ICED) (2017). Member networks list. Retrieved 26/10/ 2017 at: http://icedonline.net/member-networks/

Kenny, S. (2016). Community development today: engaging challenges through cosmopolitanism? Community Development Journal. https://doi.org/10.1093/cdj/bsv058.

King, J. (2016). Interview with James King (IIE-SRF). International Journal of Research from the Front-line, $1(2), 10-16$.

Kretzmann, J. P., \& McKnight, J. L. (1993). Building communities from the inside out: A path toward finding and mobilizing a Community's assets. Evanston: Northwestern University, Institute for Policy Research, AssetBased Community Development Institute.

Land, R. (2001). Agency, context and change in academic development. International Journal of Academic Development, 6(2), 4-20.

Leibowitz, B. (2014). Reflections on academic development: what is in a name? International Journal for Academic Development, 19(4), 357-360.

Lillis, T., Magyar, A., \& Robinson-Pant, A. (2010). An international journal's attempts to address inequalities in academic publishing: Developing a writing for publication programme. Compare: A Journal of Comparative and International Education, 40(6), 781-800.

Malcolm, J., \& Zukas, M. (2001). Bridging pedagogic gaps: conceptual discontinuities in higher education. Teaching in Higher Education, 6(1), 33-42.

Mårtensson, K., Roxå, T., \& Olsson, T. (2011). Developing a quality culture through the scholarship of teaching and learning. Higher Education Research \& Development, 30(1), 51-62. https://doi.org/10.1080 /07294360.2011.536972.

Martin, A. W. (2005). Large group processes as action research. In P. Reason \& H. Bradbury (Eds.), Handbook of action research (pp. 200-208). London: Sage.

Owen, H. (2008). Open space technology. A User's guide (3rd ed.). Oakland: Berrett-Koehler.

Parkinson, T. (2018). A trialectic framework for large group processes in educational action research: the case of academic development for Syrian academics in exile. Educational Action Research. https://doi.org/10.1080 /09650792.2018.1532803.

Parkinson, T., Zoubir, T., Abdullateef, S., Abedtalas, M., Alhaj Omar, F., Al Husni, M., Iboor, F., Ibrahim, Z., Jenkins, M., Rashwani, A., \& Shaban, F. (2018). 'We are still here': the stories of Syrian academics in exile. International Journal of Comparative Education and Development, 20(3/4), 132-147.

Pleschová, G., Simon, E., Quinlan, K. M., Murphy, J. Roxa, T., \& Szabó, M. (2013). The professionalisation of academics as teachers in higher education. European Science Foundation Position Paper. Retrieved 25/10/17 at: http:/www.esf.org/fileadmin/Public_documents/Publications/professionalisation_academics.pdf.

Quinlan, K. M., Buelens, H., Clements, M., Horn, J., \& Osterberg Rump, C. (2017). Educational enhancement in the disciplines: Models, lessons and challenges from three research-intensive universities. In B. Stensaker, L. 
Breslow, G. Bilbow, \& R. van der Vaart (Eds.), Strengthening teaching and learning in research-intensive universities: Strategies and initiatives for institutional change (pp. 43-71). London: Springer ISBN: 978-3319-56499-9.

Russell, R. L., \& Hutzel, K. (2015). Promoting through service-learning art projects. Art Education, 60(3), 6-11.

Sherab, D. and Kirk, K. (2016). Access to higher education for refugees in Jordan. Arab renaissance for democracy and development (ARDD)-legal. Retrieved 09/06/19 at: http://ardd-jo.org/reportsdocuments/access-higher-education-refugees-jordan-protection-and-sustainable-development.

Stensaker, B. (2018). Academic development as cultural work: Responding to the organizational complexity of modern higher education institutions. International Journal for Academic Development, 23(4), 274-285.

Stoecker, R. (2014). Community development. In SAGE encyclopedia of action research. https://doi.org/10.4135 /9781446294406.n67

Sugrue, C., Englund, T., Solbrekke, T. D., \& Fossland, T. (2017). Trends in the practices of academic developers: trajectories of higher education? Studies Higher Education. https://doi.org/10.1080 /03075079.2017.1326026.

Sutherland, K. A. (2018). Holistic academic development: is it time to think more broadly about the academic development project? International Journal for Academic Development, 23(4), 261-273. https://doi. org/10.1080/1360144X.2018.1524571.

Thomas, D. R. (2016). A general inductive approach for analyzing qualitative evaluation data. American Journal of Evaluation, 27(2), 237-246.

United Nations High Commission For Refugees (UNHCR) (2012). Education Strategy 2012-2016. Retrieved 25/10/17 at: http://www.unhcr.org/uk/protection/operations/5149ba349/unhcr-educationstrategy-2012-2016.html

Vollman, A. (2016). The plight of Syrian students and the obstacles they face on the path to higher education. Insight into diversity, May 2016. Retrieved 25/10/17 at: http://www.insightintodiversity.com/the-plight-ofsyrian-students/.

Watenpaugh, K., Fricke, A., King, J., Gratien, C., \& Yilmaz, S. (2014). We will stop and go no further: Syrian university students and scholars in Turkey. Davis: University of California Davis Institute of International Education.

Zembylas, M. (2013). Critical pedagogy and emotion: working through troubled knowledge in posttraumatic societies. Critical Studies in Education, 54, 176-189.

Publisher's note Springer Nature remains neutral with regard to jurisdictional claims in published maps and institutional affiliations. 